\title{
Interactions between substratum rugosity, colonization density and periwinkle grazing efficiency
}

\author{
M. Wahl ${ }^{1, *}$, K. Hoppe ${ }^{2}$ \\ ${ }^{1}$ University of Namibia, Windhoek, Namibia \\ ${ }^{2}$ Zoologisches Insitut, Universität Kiel, Olshausenstr. 40, $24098 \mathrm{Kiel}$, Germany
}

\begin{abstract}
Both surface texture and littorinid grazing are known to influence the establishment of many shallow-water benthic hard-bottom communities. However, the effects of these factors and their interactions have not yet been investigated in a quantifiable manner. This investigation aims to assess the interactive effect of both factors in a strictly standardized manner. Natural recruitment by diatoms, the barnacle Balanus improvisus and the tube-building polychaete Polydora sp. was monitored under a 2-factorial treatment: grazing by the periwinkle Littorina littorea (Factor 1; 2 levels: 1 or no snails per plate) on artificial recruitment plates of different initial surface rugosities (Factor 2; 5 levels: smooth, $0.1,0.5,1$ and $5 \mathrm{~mm}$ rugosity elements). In the absence of grazers, barnacle recruitment decreased with increasing initial rugosity, polychaete recruitment peaked at intermediate rugosities, and diatoms exhibited contrasting recruitment patterns in an in vitro and an in situ experiment. When preferred recruitment sites coincided for Polydora and B. improvisus, a competition for space could be inferred from a negative correlation between the 2 species. However, when the overlap of requirements weakened on the 5 rugosities, the relationship was positive, but was not statistically significant. Grazing efficiency by L. littorea depended on initial rugosity, generally showing minimum values on intermediate rugosities which is attributable to a mismatch between radula dimensions and surface structures in these rugosity classes. Additionally, grazing effects tended to increase with higher prey densities. As all factors - initial rugosity, grazing, colonizer species -interact with each other, the outcome of recruitment under combined factors is difficult to predict from single factor effects.
\end{abstract}

KEY WORDS: Grazing efficiency $\cdot$ Surface rugosity $\cdot$ Recruitment $\cdot$ Multiple interactions

\section{INTRODUCTION}

Any factor influencing settlement or postsettlement processes is an important component in the establishment, dynamics and structure of benthic hard bottom communities. Of all substratum properties, surface topography possibly has the greatest impact during both of these processes.

Settlement depends on the presence of larvae and propagules and on the demands that they have for a potential settlement site (Hadfield 1986). One of those

*E-mail: mwahl@zoologie.uni-kiel.de demands may be for a certain microtopography, either through active choice or passive drift into sheltered areas of reduced flow (Crisp \& Barnes 1954, Harlin \& Lindbergh 1977, Brewer 1978, Norton \& Fetter 1981, Benayahu \& Loya 1984, Raimondi 1988). The combined effects of eddies created by elevations and stillwater zones in pits may 'collect' larvae and thus enhance settlement rate (e.g. Wethey 1986, Pawlik 1993). On the other hand, many larvae actively select surface heterogeneities for settlement (e.g. Crisp 1955, Harlin \& Lindbergh 1977, Brewer 1978, Norton \& Fetter 1981, Keough \& Downes 1982, Benayahu \& Loya 1984, Raimondi 1988, Hills \& Thomason 1996, 1998). If settlers prefer different surface elements such as pits, 
crevices, elevations or slopes, a heterogeneous surface can be expected to allow niche segregation, reduce competition, and promote coexistence of species. After settlement, induction of turbulence in the boundary layer by rugosity elements (Denny 1988) may improve the supply of nutrients and the removal of wastes for early juveniles (Koehler et al. 1999), at least on the sides and tips of rugosity elements. During the most vulnerable early juvenile phase and permanently for small adults, crevices may offer shelter from predation (e.g. Keough \& Downes 1982, Witman 1985, Petraitis 1990, Dudley \& D'Antonio 1991).

The degree to which grazers are able to remove colonizers depends on the dimensions of surface contour in relation to those of the feeding apparatus (Steneck \& Watling 1982, Janssen \& Triebskorn 1987). In addition, the grip that a crawling grazer has on a surface is important in order to avoid dislocation under shear forces and should to some degree depend on the rugosity of the substratum (Hawkins \& Hartnoll 1983).

The simultaneous and interactive effects of these 2 factors on recruitment have scarcely been rigorously addressed. The only well studied type of microtopographic influence on both grazing and recruitment is the effect of surface rugosity created by barnacle colonies (Hawkins \& Hartnoll 1983, Jernakoff 1982, Lubchenco 1983, Wethey 1986, Petraitis 1990). Some authors found that fucoid sporelings may escape her-
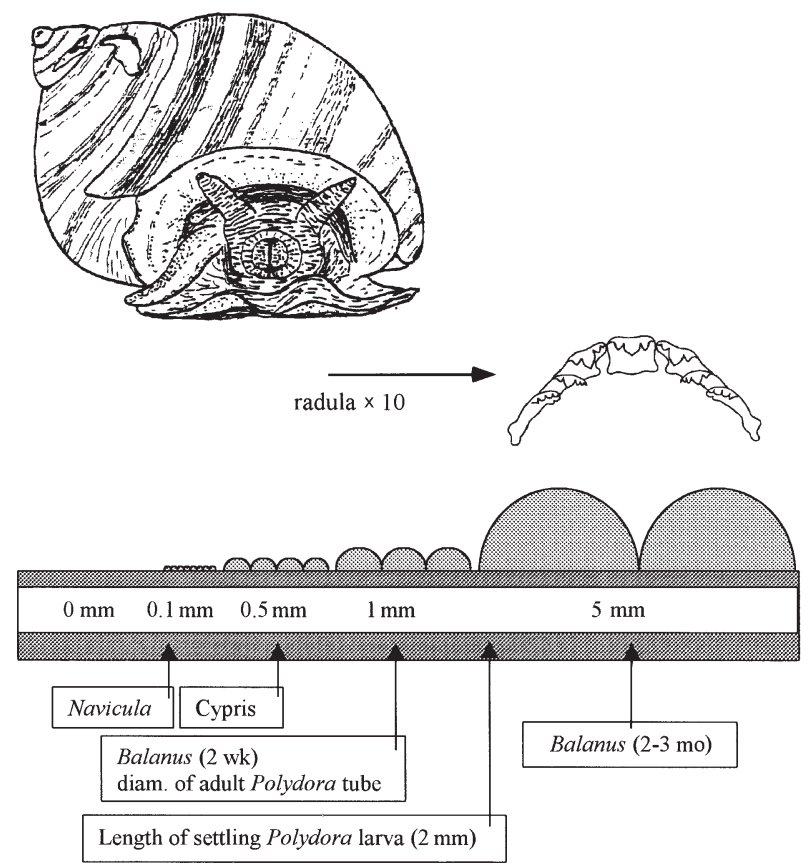

Fig. 1. Illustration of the snout of Littorina littorea, its radula (enlarged $10 \times$ on the right), different surface rugosities and some typical sizes of recruits bivory by Littorina littorea (L.) when protected in the crevices between barnacle shells (Hawkins 1981, Lubchenco 1983). As these studies deal with a naturally wide range of rugosities, they tell us little about the relevant size classes of irregularities that offer refuges from grazing and thus influence recruitment (Keough 1983). It can be expected that the protective value of surface heterogeneity depends on the relative dimensions of rugosity elements, prey and predator.

Littorina littorea is a common gastropod grazer of well known ecological importance in the North Atlantic (e.g. Petraitis 1983, 1987). It feeds on microalgae and filamentous and foliose macroalgae (Fretter \& Graham 1962, Steneck \& Watling 1982). In addition, L. littorea may affect young or delicate stages of nonprey organisms by grazing and bulldozing (Fretter \& Graham 1962, Wahl \& Soennichsen 1992). It usually scrapes prey off any hard surface with its taenioglossan radula (Steneck \& Watling 1982). In addition, it is also able to bite off pieces of macroalgae (Janssen \& Triebskorn 1987).

In this study we aim to quantify the effects of a series of calibrated surface rugosities on: (1) the recruitment of several colonizer species in the absence of the locally dominant grazer Littorina littorea; and (2) on the grazing efficiency of the latter. Finally, we try to define the multiple interactions among initial surface rugosity, recruitment density, colonizer species and grazing.

\section{MATERIALS AND METHODS}

Specimens of the periwinkle Littorina littorea with a shell length between 16 and $22 \mathrm{~mm}$ (mean length $19.5 \mathrm{~mm}$; SD $1.4 \mathrm{~mm}$ ) were collected at a depth of $1 \mathrm{~m}$ in Strande Yacht Harbour, Kiel Bight, Western Baltic $\left(54^{\circ} 22.5^{\prime} \mathrm{N}, 10^{\circ} 9.5^{\prime} \mathrm{E}\right.$ ) in May 1994 . They were kept in a 2001 closed-circuit tank with natural seawater at $20^{\circ} \mathrm{C}$ and fed with Ulva lactuca and Fucus vesiculosus.

For colonization and grazing experiments, artificial surfaces of different rugosities were created by gluing glass beads with diameters of $0.1,0.5,1$ or $5 \mathrm{~mm}$ in a dense monolayer onto $8 \times 8 \times 0.4 \mathrm{~cm}$ (length $\times$ width $\times$ height) PVC plates. The beads touched at their equators, and the lower hemispheres of the beads were completely embedded in the glue. In this manner, surfaces of defined degrees of roughness-hereafter referred to by the respective bead diameters - were obtained (Fig. 1). During the colonization process surface microtopography changed. Consequently, rugosity classification of subtrata in the text always refers to initial rugosities. For smooth surfaces (0 mm rugosity), $8 \times 8 \times 0.3 \mathrm{~cm}$ glass plates were glued onto supporting PVC panels. Silicone glue was used for the in vitro experiment as it performed well in aquarium condi- 
tions, but for unknown reasons would disintegrate in the field. A non-poisonous latex lacquer was used in all in situ experiments. To ensure identical physicochemical properties of bead and glue surfaces, all substrata were sprayed with a very thin layer of a transparent, non-toxic lacquer (see Koehler et al. 1999).

The surface of plates covered by maximally packed hemispheres of any diameter (touching at equators) is 1.79 times larger than that of smooth plates. Thus, the actual area of plates with beads (any rugosity) available for settlement was $8 \times 8 \times 1.79 \mathrm{~cm}^{2}$, that of smooth plates was $8 \times 8 \times 1 \mathrm{~cm}^{2}$. Consequently, abundance of recruits (chlorophyll a [chl a], counts) on smooth surfaces was multiplied by a correction factor of 1.79.

In order to maintain constant predation pressure while avoiding cage effects, single snails were tethered directly to the plates. We drilled $1 \mathrm{~mm}$ holes through the rim of the periwinkle shells and through the middle of each plate. One end of a polyethylene thread (0.1 mm diameter) was tied to the shell and the other end was passed through the hole in the plate and tied to a small piece of cork $\left(<1 \mathrm{~cm}^{3}\right)$. The buoyancy of the cork was just enough $(<1 \mathrm{~g})$ to keep the monofilament straight between snail and plate centre without putting any substantial mechanical strain on the animal. This was demonstrated by an apparently random distribution of grazing marks over the entire substratum surface. The length of the thread $(5.5 \mathrm{~cm})$ allowed the snails to reach the entire frontal face of the plates. The grazing area of $64 \mathrm{~cm}^{2}$ per snail falls within the reported range of natural densities of $L$. littorea between $3 \mathrm{~m}^{-2}$ in the Baltic (Wahl \& Soennichsen 1992) and over $500 \mathrm{~m}^{-2}$ in the North East Atlantic (Bertness et al. 1983, Lubchenco 1983, Petraitis 1987).

Expt I: Grazing on microalgae-in vitro. A total of 100 plates, i.e. 20 plates of each rugosity class $(0,0.1$, $0.5,1$ and $5 \mathrm{~mm}$, respectively), were kept in a flume $\left(20^{\circ} \mathrm{C}\right.$; volume $200 \mathrm{l}$, mean water velocity $10 \mathrm{~cm} \mathrm{~s}^{-1}$; illumination by two $40 \mathrm{~W}$ daylight tubes in a simulated 14:10 h day:night cycle). The flume water was Kiel Bight sea water with a salinity of $18 \mathrm{ppm}$. It was enriched with nutrients and diatoms by adding $5 \mathrm{l}$ of a Navicula sp. culture at exponential growth phase (f/2 medium). Within $3 \mathrm{wk}$ the plates were covered with a dense but thin layer of diatoms. One periwinkle was tethered to each of 10 plates of each rugosity. The other 10 plates of each rugosity served as ungrazed controls. 'Grazed' and 'ungrazed' plates of the same rugosity were paired. Pairs were positioned randomly in a large flow-through tank (18 ppm, $20^{\circ} \mathrm{C}$ ). Pairing compensated for possible spatial heterogeneity (light, turbulence, etc.) in the tank. Snails were allowed to graze for $48 \mathrm{~h}$. Subsequently, the abundance of diatoms on grazed and ungrazed (= control) plates was obtained by quantita- tive chl a analysis (see 'Microalgae quantification') as a relative measure of biomass.

Expt II: Grazing on microalgae - in situ. The experimental design allowed 80 plates to be fastened to PVC rods of $2 \mathrm{~m}$ length. A paired design was chosen to compensate for naturally patchy settlement. Pairs consisting of 1 'ungrazed' (control) and 1 'grazed' (treatment) plate of the same initial rugosity were attached side by side. Subsequently, snails were tethered to the 'grazed' plates. Each of the 4 PVC rods supported 20 vertically attached plates ( 2 pairs of each of the 5 rugosity treatments) distanced by double plate length. Arrangement of pairs on individual rods was randomised. Plates were exposed to colonization at $1 \mathrm{~m}$ depth at Kiel Holtenau Tonnenhof (Kiel Bight, Western Baltic) from 19 August through 19 September 1994. At the end of the experiment chl a was quantified on every plate (see 'Microalgae quantification'). During exposure some periwinkles and plates were lost. Only the results of complete pairs, consisting of one ungrazed plate and one plate with living and active snail by the end of the experiment, were analyzed.

Expt III: Grazing on macrocolonizers-in situ. The same set-up of treatment and control plates as in Expt II was exposed from 27 September to 18 November 1994. After retrieval, the main macrofoulers (Balanus improvisus and Polydora sp.) were individually counted under a dissecting microscope $(30 \times$ to $60 \times)$. As in Expt II, only complete pairs were taken into account (34 pairs).

Microalgae quantification. Chl a determination was performed by a hot ethanol method modified after Nusch (1980). Individual plates were put 'fouled side down' in Petri dishes containing $30 \mathrm{ml} \mathrm{(50} \mathrm{ml}$ for the $5 \mathrm{~mm}$ rugosity plates) of boiling $96 \%$ ethanol, which did not dissolve lacquer or glue. Chlorophyll was extracted for $14 \mathrm{~h}$ in darkness at room temperature. The extracts were filtered through GMC filters. Extinction of the filtrate was measured at $665 \mathrm{~nm}$ within $1 \mathrm{~h}$. Subsequently, $20 \mathrm{ml}$ of the filtrate was acidified with $0.1 \mathrm{ml} 2 \mathrm{M} \mathrm{HCl}$ and measured again for phaeophytin correction. Chl a content was calculated as:

$$
\text { chl } a=29.6 \times\left(E 665_{\mathrm{b}}-E 665_{\mathrm{a}}\right) \times v /(1 \times A)
$$

where chl $a=$ concentration of chl $a$ in $\mu g \mathrm{~cm}^{-2}$, $E 665_{\mathrm{b}}=$ extinction of extract at $665 \mathrm{~nm}$ before acidification, $E 665_{\mathrm{a}}=$ extinction of extract at $665 \mathrm{~nm}$ after acidification, $V=$ volume of solvent in $\mathrm{ml}, l=$ path length of photometer vial $(1 \mathrm{~cm}), A=$ extracted area in $\mathrm{cm}^{2}$.

A correction coefficient of $29.6\left(\mathrm{ml} \mathrm{gg}^{-1} \mathrm{~cm}^{-1}\right)$ was calculated from the acid ratio for chl a phaeophytin and the absorption coefficient for chl $a$ in ethanol (Nusch 1980).

Radula characteristics. After the experiments, 25 periwinkles from Expt III were killed by deep freezing 


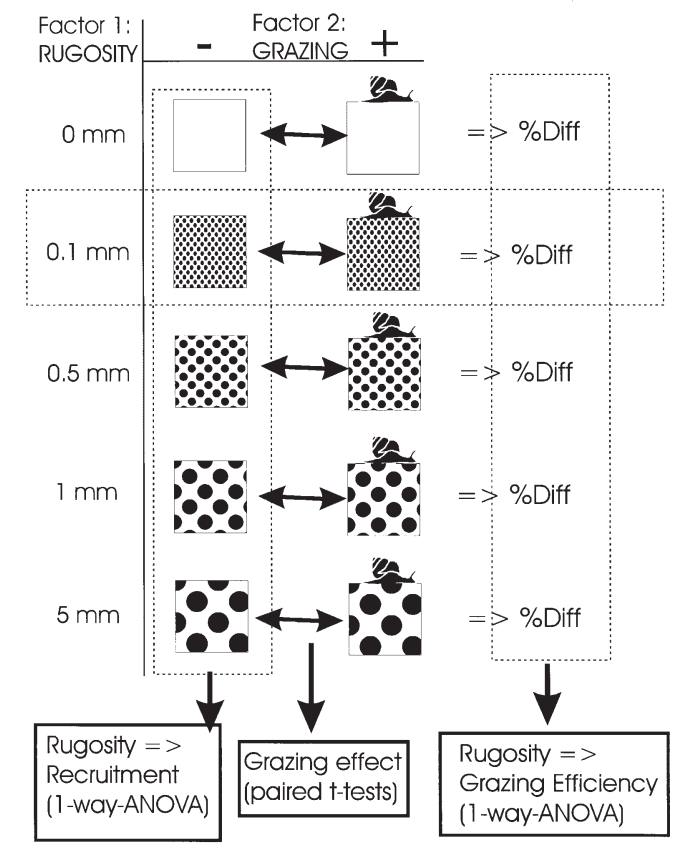

Fig. 2. Treatment and data combinations for analyses. Dotted frames exemplify data groupings for analyses

and then dissected. The radulae were removed intact and their widths about $1 \mathrm{~mm}$ behind the foremost end were measured under a dissecting microscope equipped with a Zeiss micrometer.

Statistics. Since no block effect was detected, the data of the 4 rods (in situ experiments) could be pooled.

After transformation of variables (log [chl a]; arcsine[abundance]) variance was homogeneous [F-test, Cochran's test]).

Chl a content (as a proxy for diatom abundance) and macrofouler abundance data were analysed. Paired $t$-tests between grazed and ungrazed paired plates of a given rugosity yielded effects of grazing.

A preliminary 2-way ANOVA with the factors rugosity (5 levels) and grazing ( 2 levels) revealed significant interaction between the 2 factors for most settlers. This could be due to an interaction between rugosity and grazing and/or between density of foulers (depending on rugosity) and grazing. The following approach was designed to analyze effects independently (Fig. 2). Data from ungrazed plates were analyzed by a 1-way ANOVA for effects of rugosity on recruitment of foulers independently from grazing effects. The \% difference in settler abundance between paired ungrazed and grazed substrata of a given rugosity provided grazing efficiency data which were independent of rugosity/recruitment interactions. Grazing efficiency differences among rugosities were analyzed by a 1-way ANOVA.
Post-hoc comparisons were done by Tukey's HSD or by HSD-test for unequal Ns when necessary. If not specified otherwise, all p-values in 'Results' section refer to ANOVA or HSD post-hocs.

In order to check for a relationship between density of foulers and grazing efficiency unconfounded by initial surface rugosity effects, these 2 variables were ranked within rugosity categories (within $0 \mathrm{~mm}$ treatment, within $0.1 \mathrm{~mm}$ treatment, etc.), then pooled across all rugosity categories and analysed by Spearman rank correlation.

\section{RESULTS}

\section{Expt I: Grazing on microalgae-in vitro}

The ungrazed surfaces carried dense diatom layers dominated by Navicula sp.; chl a contents ranged from 1.5 to $15.7 \mu \mathrm{g} \mathrm{cm}^{-2}$. Overall influence of initial rugosity on diatom recruitment was significant ( $<<0.05$, Table 1 ). Posthoc HSD-test for unequal Ns showed that diatom assemblages grew significantly denser on smooth surfaces than on $1 \mathrm{~mm}$ rugosity, with the other rugosities featuring intermediate diatom densities (Fig. 3).

The diatom density, represented by chl a content, was significantly lower on grazed than on ungrazed plates (paired $t$-test, $\mathrm{p}<0.0001$ ) due to grazing effects (ingestion plus bulldozing) by Littorina littorea. The effect of grazing was most conspicuous on smooth sur-

Table 1. Overall ANOVA results for (a) recruitment, (b) grazing efficiency, and (c) paired $t$-test significances for grazing effect $\left({ }^{*} \mathrm{p}<0.05,{ }^{* *} \mathrm{p}<0.01,{ }^{* * *} \mathrm{p}<0.001\right)$. Diat 1 : laboratory; Diat 2: in situ

(a) Recruitment (1-way ANOVA)

\begin{tabular}{lcccccc} 
& df & SS & MS & $F$ & $p$ & \\
\hline Diat 1 & 4 & 0.1287 & 0.0413 & 3.1139 & 0.0268 & $*$ \\
Diat 2 & 4 & 0.2540 & 0.1025 & 2.4765 & 0.0680 & \\
Balanus & 4 & 0.1857 & 0.0185 & 10.0391 & 0.0000 & $* *$ \\
Polydora & 4 & 0.0747 & 0.0227 & 3.2885 & 0.0255 & $*$ \\
(b) Grazing efficiency (1-way ANOVA) & & &
\end{tabular}

(b) Grazing efficiency (1-way ANOVA)

\begin{tabular}{|c|c|c|c|c|c|c|}
\hline & df & SS & MS & $F$ & $\mathrm{p}$ & \\
\hline Diat 1 & 4 & 0.2924 & 0.1439 & 2.0323 & 0.1105 & \\
\hline Diat 2 & 4 & 0.7360 & 0.0172 & 42.7236 & 0.0000 & *** \\
\hline Balanus & 4 & 0.7437 & 0.1556 & 4.7800 & 0.0044 & ** \\
\hline Polydora & 4 & 0.7130 & 0.0827 & 8.6193 & 0.0001 & *** \\
\hline \multicolumn{7}{|c|}{ (c) Grazing effect (pairwise $t$-test) } \\
\hline & $0 \mathrm{~mm}$ & $0.1 \mathrm{~mm}$ & $0.5 \mathrm{~mm}$ & $1 \mathrm{~mm}$ & $5 \mathrm{~mm}$ & \\
\hline Diat 1 & $* * *$ & $* * *$ & & & ${ }^{*}$ & \\
\hline Diat 2 & $* * *$ & $* * *$ & & & ** & \\
\hline Balanus & & ${ }^{*}$ & & & $* *$ & \\
\hline Polydora & ** & ** & $* * *$ & $* * *$ & $* *$ & \\
\hline
\end{tabular}


faces where snails removed ca $90 \%$ of the diatoms. The grazing efficiencies tended to decrease with increasing rugosity but did not differ significantly among rugosities.

Grazing efficiency was not significantly related to diatom density (Spearman rank, p > 0.05).

The combined effects of initial rugosity on diatom recruitment and grazing efficiency led to a steady increase of diatom biomass from smooth to rough substrata (0 to $5 \mathrm{~mm}$ rugosity) in the presence of grazers.

\section{Expt II: Grazing on microalgae-in situ}

After 1 mo exposure in the field, the ungrazed plates were covered with microalgae, but carried almost no macroflora or -fauna. The microalgal layers consisted mainly of a solitary diatom belonging to the genus Navicula (a species different from that in Expt I) and filamentous colonies of the diatom Melosira sp. Chl a contents ranged from 1.1 to $4.0 \mu \mathrm{g}$ $\mathrm{cm}^{-2}$ on ungrazed plates. Consequently, chl a concentration - and presumably diatom density - was lower by $25 \%$ (1 $\mathrm{mm})$ to $75 \%(0 \mathrm{~mm})$ compared to the plates colonized by culture diatoms in Expt I. As a trend, chl a concentrations increased with increasing initial rugosity (Fig. 4).

Diatom densities were lower on grazed than on ungrazed plates (paired $t$-test, $\mathrm{p}<0.0001$, Table 1 ). This decrease was significant on $0,0.1$ and $5 \mathrm{~mm}$ rugosities (Table 1). Grazing efficiency was lowest on intermediate rugosities ( 0.5 and $1 \mathrm{~mm}$ ) whereas highest grazing rates occurred on smooth surfaces $(\mathrm{p}<$ 0.05, Fig. 4). Grazing efficiency increased in significant steps $(1<5<0.1<0$ mm rugosity. Grazing efficiency was not influenced by diatom density (measured as chl a concentration, Spearman rank, $\mathrm{p}>0.05)$.

As in the in vitro experiment, the combined effects of initial rugosity on diatom recruitment (measurable on ungrazed plates) and grazing efficiency led to a progressive increase of diatom biomass from smooth to rougher substrata in the presence of grazers, reaching a maximum on the $1 \mathrm{~mm}$ rugosity plates.

\section{Expt III: Grazing on macrocolonizers - in situ}

After 2 mo of exposure in late summer, most of the ungrazed surfaces were covered

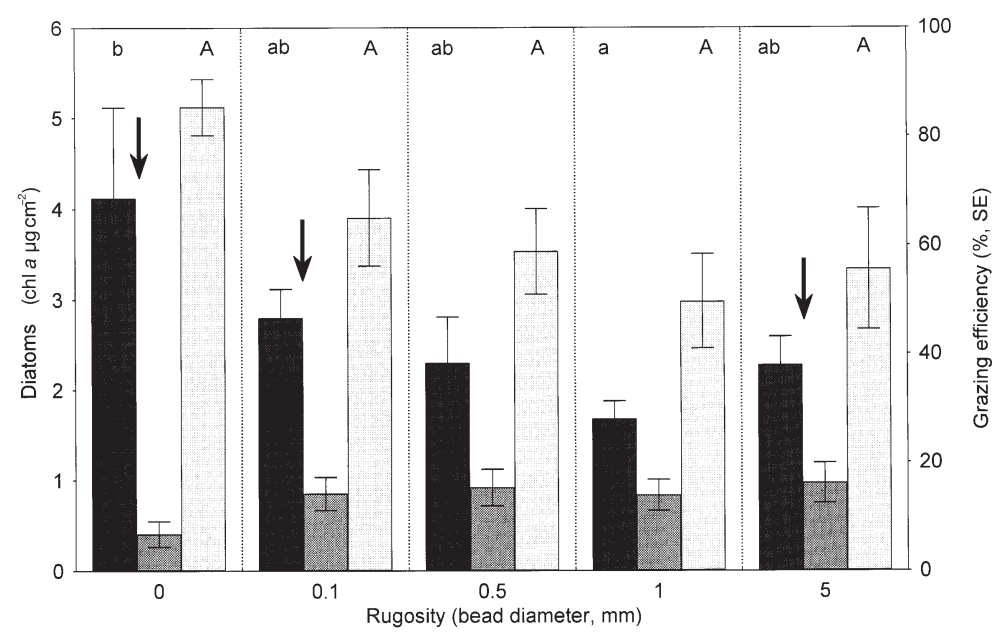

Fig. 3. In vitro experiment: density of diatoms on ungrazed (black columns) and grazed (dark grey columns) plates, and grazing efficiency $(=\%$ reduction of colonizers on grazed vs ungrazed plates, light grey columns) split by surface rugosity $(x$-categories). Error bar $=$ standard error. Capital and lower case letters at top of the graph indicate treatment differences among grazing efficiencies and among colonizer densities on ungrazed plates, respectively: treatments sharing a letter do not differ significantly. Vertical arrows indicate a significant grazer effect

by microalgae, which were not identified to species level and did not enter analysis in this experiment. No macroflora was found except for a few minute filaments of unidentified green and red algae. Barnacles Balanus improvisus and sedentary polychaetes Polydora ciliata and $P$. ligni were the dominant macrofaunal colonisers. Very low numbers of the mussel Mytilus edulis, the ascidian Ciona intestinalis, and the hydrozoan Gonothyrea loveni, settled in this sea-

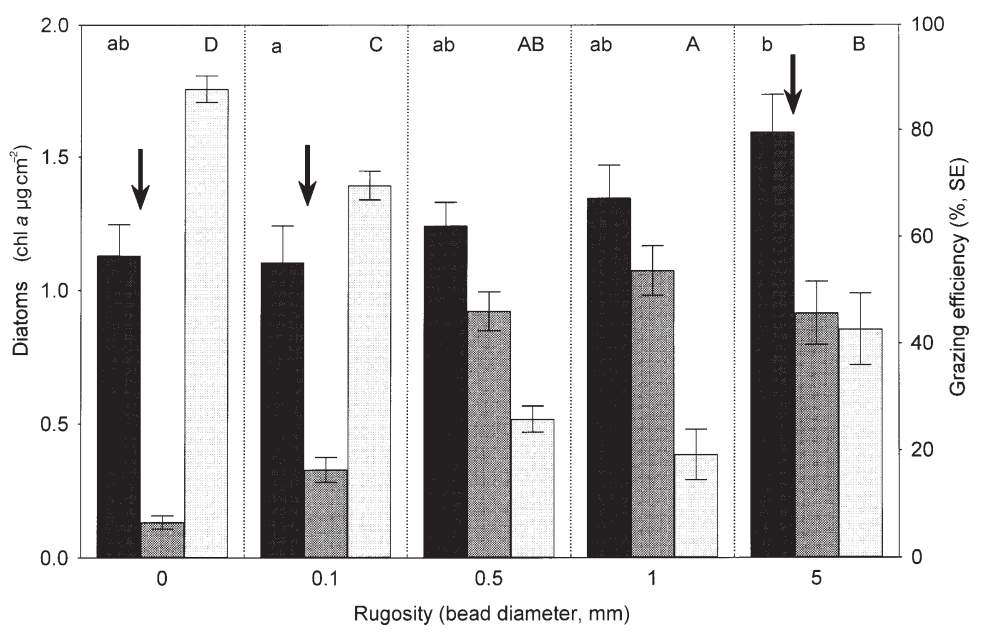

Fig. 4. First in situ experiment: density of diatoms on ungrazed (black columns) and grazed (dark grey columns) plates, and grazing efficiency (light grey columns) split by surface rugosity ( $x$-categories). Symbols and their interpretation as in Fig. 3 


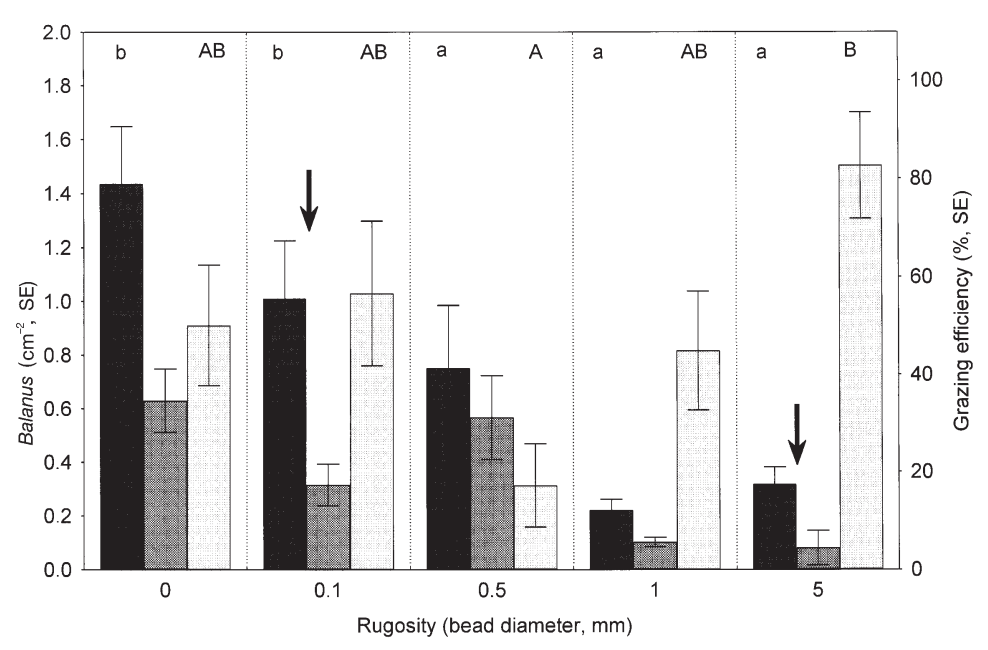

Fig. 5. Second in situ experiment: density of Balanus improvisus on ungrazed (black columns) and grazed (dark grey columns) plates, and grazing efficiency (light grey columns) split by surface rugosity ( $x$-categories). Symbols and their interpretation as in Fig. 3

son. These 3 latter species were not taken into account because of their rarity.

On ungrazed plates, the densities of Balanus improvisus decreased from smooth to rougher substrata, exhibiting significantly higher numbers on 0 and $0.1 \mathrm{~mm}$ rugosities compared to $0.5,1$ and $5 \mathrm{~mm}$ rugosities (4 comparisons: $0.0001<p<0.05$, Fig. 5, Table 1). Barnacles grew exclusively in crevices between beads with the exception of $5 \mathrm{~mm}$ substrata, where a substantial proportion of the population (>20\%) had attached on top of the beads.

Grazed substrata carried significantly lower densities of barnacles (paired $t$-test, $\mathrm{p}<0.0001$, Table 1), which was attributed to snail grazing. On average, Balanus improvisus density on grazed plates was lower than ungrazed controls by $48 \%$. Grazing efficiency was significantly lower on the $0.5 \mathrm{~mm}$ compared to the $5 \mathrm{~mm}$ rugosity (Table 1, Fig. 5), with the remaining rugosities showing intermediate grazing efficiencies.

Grazing efficiency was positively correlated to barnacle density (Spearman $\mathrm{R}=+0.47, \mathrm{p}=$ $0.005)$, i.e. on a given type of substratum the proportion of juvenile barnacles removed increased with the number of barnacles present per unit area. This abundance-dependent grazing is completely masked by direct effects of initial rugosity on grazing efficiency and is no longer detectable when comparing across treatments (Spearman $\mathrm{R}=+0.094, \mathrm{p}=0.6$, Fig. 5)

In the presence of grazers, the densest populations of barnacles developed on the smoother surfaces.
Tubes of the spionid polychaete Polydora sp. were invariably restricted to crevices between beads. Their population density on ungrazed substrata was highest on $1 \mathrm{~mm}$ substrata and lowest on $0.1 \mathrm{~mm}$ substrata ( $p<0.05$, Fig. 6, Table 1).

Grazing efficiency tended to decrease with increasing initial rugosity, and was significantly lowest on $5 \mathrm{~mm}$ rugosities ( $\mathrm{p}<$ 0.01, Fig. 6, Table 1). Grazing efficiency improved with increasing densities of polychaetes (Spearman R $=0.5$, p < 0.01). However, this effect was masked by effects of initial rugosity on grazing efficiency when comparing across treatments (Spearman $\mathrm{R}=+0.21, \mathrm{p}=0.7$ ).

In the presence of grazers, highest densities of polychaetes were found on the coarsest substrata (1 and $5 \mathrm{~mm}$ ).

When analysed within rugosity treatments (i.e. independently of rugosity effects), the densities of barnacles and polychaetes on ungrazed plates correlated negatively (Spearman $\mathrm{R}=-0.46$, $\mathrm{p}<$ 0.01, Fig. 7). When split by substratum types the accompanying reduction of sample size leads to a loss of significance in most instances. However, the apparent negative relationship persists with the notable exception of the coarsest substrata. On the other hand, the closest negative relationship was observed on the $1 \mathrm{~mm}$ substrata (Spearman $\mathrm{R}=0.71, \mathrm{p}=0.03$ ). These 2 extremes are characterised by maximum polychaete density on $1 \mathrm{~mm}$ substrata and a shift in microhabitat (from crevices to bead tops) for barnacles on $5 \mathrm{~mm}$ substrata, respectively.

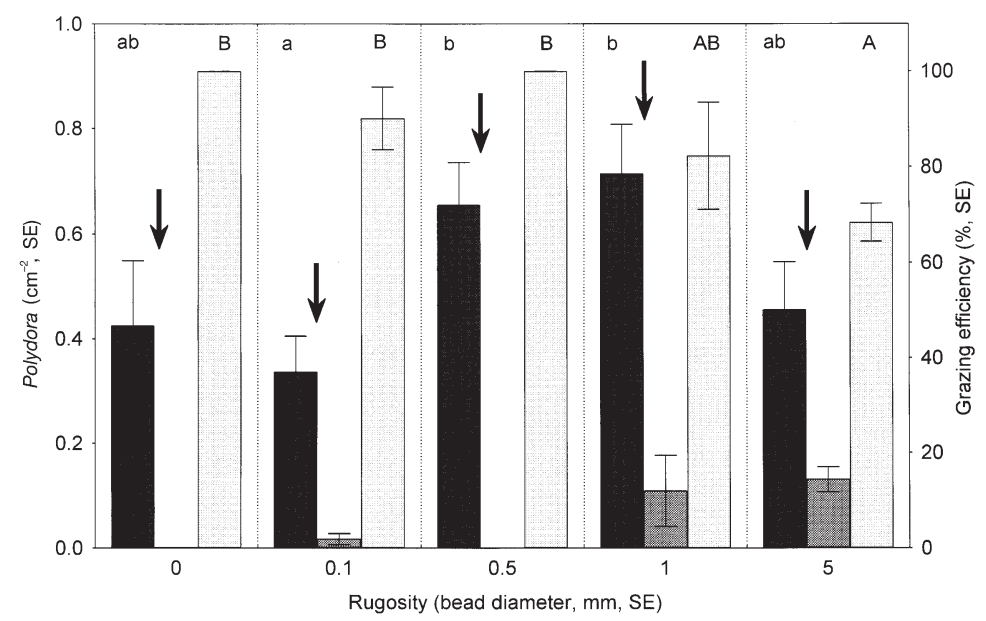

Fig. 6. Second in situ experiment: density of Polydora sp. on ungrazed (black columns) and grazed (dark grey columns) plates, and grazing efficiency (light grey columns) split by surface rugosity ( $x$-categories). Symbols and their interpretation as in Fig. 3 


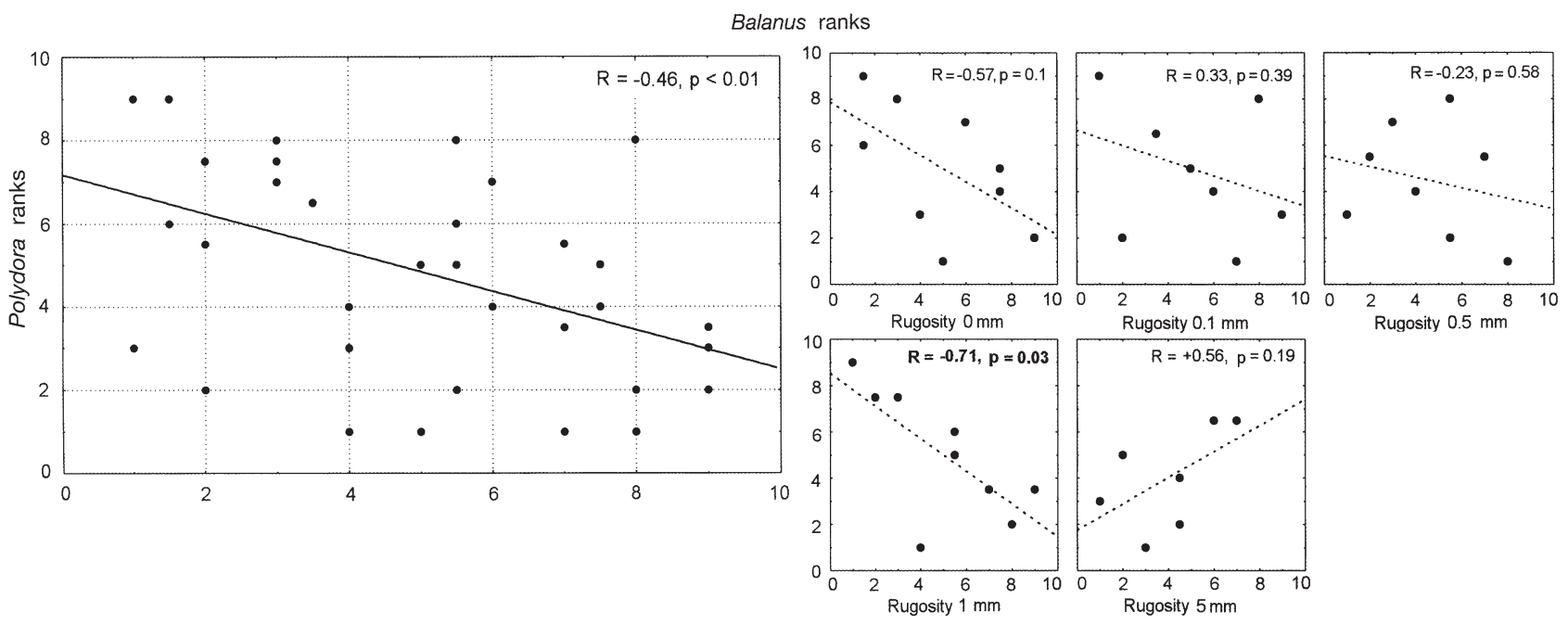

Fig. 7. Rank-correlation between Balanus improvisus densities and Polydora sp. densities, pooled (upper plot) and split for substratum rugosities (lower plots)

\section{Radula characteristics}

Dissection of 25 specimens of Littorina littorea with a mean shell length of $19.5 \mathrm{~mm}(\mathrm{SE}=0.27 \mathrm{~mm})$ revealed a mean radula width of $0.43 \mathrm{~mm}(\mathrm{SE}=0.006 \mathrm{~mm})$. In this size class of periwinkles, radula width did not correlate with shell size (Spearman $R=0.12$, $p=0.195$ ).

\section{DISCUSSION}

This investigation reveals the existence of multiple interactions between substratum microtopography ('rugosity'), population density of 3 taxa of fouling species and disturbance by the locally important grazer Littorina littorea.

After 3 to 4 wk of in situ exposure of ungrazed plates, recruitment of diatoms (assessed as chl $\mathrm{a} \mathrm{cm}^{-2}$ ), barnacles and sedentary polychaetes differed among rugosities. On grazed plates, the presence and/or browsing activity of the snail invariably reduced colonizer densities. The size of effect depended on initial rugosity and, with regard to barnacles and polychaetes, on prey density. A further observed interaction was a negative relationship between barnacle and polychaete populations under undisturbed (ungrazed) conditions.

\section{Substratum microtopography versus population density}

Because no browsing by fishes, isopods, amphipods or any other grazer was observed during regular sur- veys (2 to 4 SCUBA inspections per week), control plates without tethered Littorina littorea were considered 'ungrazed'. Also, the experimental site was not subject to any physical disturbance during the period under consideration. Consequently, any consistent and significant differences in population density among the 5 categories of surface microtopography are considered to reflect settlement 'preferences' (active or passive) of the foulers and/or postsettlement processes such as reproduction (for diatoms only), intra- or interspecific competition, mortality, etc.

Diatoms colonised both crevices and bead surfaces. They follow Keough \& Downes' (1982) 'ping-pong' model of settlement without active choice, where no topographical feature is preferred or avoided. In vitro and in situ colonisation produced contrasting results. In the flume, population density (as inferred from chl a concentrations) decreased with increasing initial substratum rugosity, whereas in the field the opposite trend was observed: diatom numbers steadily increased with increasing initial substratum rugosity. This latter pattern is identical to the results of Koehler et al. (1999) in a similar investigation (same methods and location, different year and season). It remains unclear whether the substantially higher population density on all in vitro substrata, the differing specific affiliation of the colonizing diatoms, and/or the continuous and relatively strong current in the flume are responsible for the apparent inconsistency between systems.

In the absence of grazers, Balanus improvisus recruitment decreased with initial rugosity. This contrasts with the findings of Koehler et al. (1999), where 
highest abundance of the same species was found on 0.5 and $1 \mathrm{~mm}$ rugosities. One possible explanation is that in the present study Polydora sp. outcompeted barnacles on the 3 coarser rugosities (see below). These sedentary polychaetes were 5 times less abundant in the Koehler (1999) study. On the other hand, similar preferences of $B$. improvisus for low initial rugosity surfaces were reported by Hills et al. (1999) and Andersson et al. (1999).

On the 3 coarsest substrata Balanus improvisus preferentially grew in the crevices between beads-exclusively so on 0.5 and $1 \mathrm{~mm}$ rugosities. The crevices between $0.1 \mathrm{~mm}$ beads were too small to accommodate cyprid larvae or juvenile barnacles. Only the tops of $5 \mathrm{~mm}$ beads were colonized by a substantial proportion of the population. As this occurred at one of the lowest population densities, intraspecific crowding (i.e. shortage of 'potential settling sites', as described for Semibalanus balanoides by Hills \& Thomason 1996), is not a plausible explanation. The abundance of potential competitors for space (i.e. Polydora sp. see below) was lower on this substratum type than on intermediate rugosities. The observed shift in microhabitat preference may rather be related to the scale of rugosity. Koehler et al. (1999) report an identical preference behavior of B. improvisus. The general preference for crevices on the intermediate rugosity scales is consistent with earlier studies (Crisp \& Barnes 1954, Crisp 1955, Huxley et al. 1984, Crisp \& Bourget 1985, Hills \& Thomason 1996). Interestingly, on even smaller scales, surface ripples with a wavelength of $1 \mu \mathrm{m}$ on the periostracum of Mytilus edulis shells reduce settlement by $B$. improvisus (Lenz 1998). It seems that the widely acknowledged rugophilicity of barnacles (e.g. Huxley et al. 1984, Crisp \& Bourget 1985, Hills \& Thomason 1998) is scale dependent and limited to rugosities larger than $0.1 \mathrm{~mm}$ and smaller than $5 \mathrm{~mm}$. While active choice of cyprid larvae has repeatedly been demonstrated (e.g. Knight-Jones \& Crisp 1953, Crisp 1955, Hills \& Thomason 1996), physical processes such as passive deposition and resuspension and specific microhydrodynamic regimes may contribute to the pattern (e.g. Wethey 1986, Pawlik \& Butman 1993). While Koehler et al. (1999) suggest that the observed recruitment pattern results mainly from a corresponding settlement pattern, high mortality rates in the first hours or days after settlement may contribute substantially to the results (Gosselin \& Qian 1997).

When crevices of dimensions suitable for settlement and tube-building were available (rugosities 0.5 to $5 \mathrm{~mm}$ ), the sedentary polychaetes of the genus Polydora invariably built their tubes in the crevices. An identical pattern was described by Koehler et al. (1999). Polydora sp. reached highest densities on ungrazed substrata of intermediate initial rugosity $(0.5$ and $1 \mathrm{~mm})$. Again, this pattern may result from active larval choice, physical processes, or both (e.g. Pawlik \& Butman 1993) and/or from early mortality (Gosselin \& Qian 1997).

\section{Substratum microtopography versus grazing efficiency}

The grazing activity (ingestion or bulldozing) of the snail tethered to the treatment plates was considered the main causal factor creating differing patterns between paired substrata. It could be argued that the mere presence of the snail might also influence recruitment in 3 ways other than grazing: (1) the snail's foot temporarily shelters a shifting substratum area of ca $2 \mathrm{~cm}^{2}$ from settlement. This effectively reduces the plate area available for settlement at any given time by $3 \%$, which is negligible in this context as observed recruitment differences between ungrazed and grazed plates were at least an order of magnitude larger; (2) mucus trails secreted by the foot may represent an unfavourable settlement surface (but it is difficult to explain 'grazing' differences among rugosities and among prey densities by this mechanism); and (3) snail exudates could represent a negative settlement cue for the fouling species considered here. The latter seems unlikely since Littorina littorea shells are commonly fouled by Navicula sp., Polydora sp. and Balanus improvisus (Wahl \& Soennichsen 1992).

With regard to all recruiting species, grazing efficiency, i.e. the observed proportional differences between 'population densities' (chl a concentration, abundances) on ungrazed versus grazed substrata of a treatment pair, differed among rugosities. Feeding traces suggested that snail foraging rates were similar among rugosities although this was not quantified. If foraging and grazing rates were similar, differences in grazing efficiency (\% reduction of prey) could have been caused by availability of prey, by accessibility of prey, or both. Availability (or density) of prey will be treated later.

In this context we use the term 'prey' for individuals killed or removed by Littorina littorea regardless of whether they feature in the snail's regular diet or were 'accidental victims' of bulldozing. Accessibility of prey recruiting into crevices is a function of the ratios between crevice dimensions, prey size, and the respective sizes of teeth, radula and snout of the snail.

Even though the radula of Littorina littorea has been studied before (Fretter \& Graham 1962, Steneck \& Watling 1982, Janssen \& Triebskorn 1987), only few size references are available. The medium-sized periwinkles (16 to $22 \mathrm{~mm}$ ) used in this study had radulae of a fairly uniform width $(0.4$ to $0.5 \mathrm{~mm})$, independent of shell size. According to Janssen \& Triebskorn (1987), 
the 7 individual teeth per row are between 0.1 and $0.3 \mathrm{~mm}$ long and have serrated terminal parts, all teeth simultaneously contact a smooth surface and individual teeth may reach into crevices of appropriate dimensions (Fig. 2).

Grazing efficiency on diatoms was highest on smooth and $0.1 \mathrm{~mm}$ plates and lowest on the intermediate 0.5 and $1 \mathrm{~mm}$ surfaces. Smooth surfaces offer no shelter. Crevices between $0.1 \mathrm{~mm}$ beads are accessible to individual teeth. On 0.5 and $1 \mathrm{~mm}$ rugosities, the radula teeth only reach the upper regions of the glass beads, crevices being deeper than the length of individual teeth and too narrow to accommodate the entire radula. Grazing efficiency was lowest on these substrata. Grazing efficiency increased again on $5 \mathrm{~mm}$ beads, where the whole snout with the radula fits into the gaps between beads. Under the combined effects of recruitment preferences and postsettlement processes such as grazing pressure, densest diatom populations develop on the rougher surfaces.

A similar picture appears for grazing on barnacles. The conspicuous maximum of grazing efficiency on $5 \mathrm{~mm}$ rugosities is caused by the combined effects of enhanced accessibility and a less pronounced restriction of the barnacles to crevices. Predation was least effective on $0.5 \mathrm{~mm}$ rugosities. A 0.5 to $0.6 \mathrm{~mm}$ long cyprid (Buchholz 1951) may find shelter between the 0.5 or $1 \mathrm{~mm}$ beads (see Fig. 1) during a barnacle's most vulnerable ontogenetic phase between settlement and calcification. Highest barnacle densities developed on the finely granulated and smooth substrata. Possible causes are high recruitment rates on these rugosities, moderate grazing efficiency and low abundances of competitors for space (see 'Prey density versus grazing efficiency').

In contrast to the previous patterns, grazing efficiency on Polydora sp. was very high on all rugosities, with a slight reduction towards the coarser surfaces. These polychaetes become more accessible when outgrowing the smaller crevices without simultaneously becoming more resistant to grazing like barnacles do. This process will take longer in deeper crevices ( 1 and $5 \mathrm{~mm})$, retarding susceptibility to grazing. The reduced mortality in the relatively accessible $5 \mathrm{~mm}$ crevices may be due to the fact that the tubes were invariably wedged into the edge between bead and glue.

\section{Prey density versus grazing efficiency}

Grazing efficiency not only varied with initial surface rugosity but also showed some density-dependence. Independently of initial rugosity (i.e. when comparing among replicates within treatment types) proportional snail-caused mortality of both barnacles and polychaetes increased with prey density. This is not a result of higher encounter rates, since not only the absolute numbers of prey killed increase but also the proportion of the prey population affected. An increase in snail foraging activity in response to prey density is not a satisfactory explanation either: since barnacle and polychaete densities correlate inversely (see 'Interaction of colonizer species'), high barnacle density triggering snail grazing would entail increased mortality of polychaetes present at low density, and thus blur the correlation. If juvenile Balanus improvisus and Polydora sp. are not merely accidental 'by-catch', but are actually targeted and consumed by the snail, abundance-dependent consumption could explain the observed patterns. However, these 'prey' species have never been reported to feature in Littorina littorea's diet and the issue has to remain hypothetical.

\section{Interaction between colonizer species}

Independently of substratum effects, recruitment by barnacles and polychaetes correlated inversely. When analysing this relationship within rugosity categories and thereby reducing $\mathrm{N}$ by a factor of 5 , the significance is lost in all instances but for the $1 \mathrm{~mm}$ rugosity. However, the trend for an inverse relationship between the 2 fouling species persists with the notable exception of the $5 \mathrm{~mm}$ rugosity, where it turns (nonsignificantly) positive. Apparently, the 2 species are competing for preferred settlement sites in crevices. The negative correlation is closest on rugosities where barnacles $(0.1 \mathrm{~mm})$ or polychaetes $(1 \mathrm{~mm})$ reach maximum densities, and turns non significantly positive where barnacles shift from crevices to bead tops (5 $\mathrm{mm}$ ), thus reducing resource overlap with polychaetes.

\section{CONCLUSIONS}

While it is widely accepted that larval supply, settlement preferences, substratum properties, interaction with previous settlers, early juvenile mortality by nonpredation causes, physical disturbance, competition and predation play important roles for the dynamics in benthic communities, no general consensus on their relative importance is achieved (e.g. Caley et al. 1996, and references therein). This is presumably so because the relative contribution of these factors varies between locations and between systems studied. Additionally, as shown in the present investigation, interactions among several factors are likely to modify their respective effect strengths. 
Larval flux into a system is a good predictor for settlement rates - if quantified correctly (Gaines \& Bertness 1993). However, settlement patterns may be drastically modified within hours by early juvenile mortality, itself often dependent on settlement rates and substratum properties (Holm 1990, Gosselin \& Qian 1997), or within weeks by progressively unselective use of a decreasing resource, space (Koehler et al. unpubl.). Settlement preferences interact with settlement rates and may be modulated by the presence of previously settled conspecifics, congenerics or individuals of other species (e.g. Walters et al. 1996, Hills \& Thomason 1998, Wahl 2001). The impact of physical disturbance and of predation may be reduced by the presence of refuges on rough surfaces (e.g. Keough \& Downes 1982, Petraitits 1990, Dudley \& D'Antonio 1991), and predation levels may be a function of disturbance regime (e.g. Menge 1991). In a functional web of this level of connectivity, single effects are influenced by multiple direct and indirect interactions and cannot be expected to display a static strength. Rather they should vibrate around some median value with varying amplitude and frequency.

In the system that we studied, all factors - initial surface rugosity, recruitment density, colonizer species and predation -interact with each other. Initial surface rugosity influences population density and grazing efficiency, grazing reduces population density and is itself density-dependent in some instances, population densities influence each other. As a result single effect strengths vary with changing co-factors. Grazing tends to be of low importance on intermediate rugosities - unless the prey outgrows the refuges without developing alternative protection (Polydora sp.). Recruitment preferences for certain rugosities may (diatoms 1, Polydora sp.) or may not (diatoms 2, barnacles) be masked by grazing. Competition for refuges varies with crevice size and population density.

Consequently, even under the tightly controlled conditions of this experiment, with qualitatively and quantitatively determined predation and substratum characteristics, the outcome of recruitment is difficult to predict.

Acknowledgements. We are grateful for essential field assistance and diving support from S. Duerr, P. Enderlein, M. Lenz, M. Molis, and H. Soennichsen. Most helpful and constructive comments by J. Thomason and 3 anonymous referees helped improve the manuscript.

\section{LITERATURE}

Andersson M, Berntsson K, Jonsson P, Gatenholm P (1999) Microtextured surfaces: towards macrofouling resistent coatings. Biofouling 14:167-180
Benayahu Y, Loya Y (1984) Substratum preferences and planulae settling of two Red Sea Alcyonaceans: Xenia macrospiculata (Gohar) and Parerythropodium fulvum fulvum (Forskål). J Exp Mar Biol Ecol 83:249-261

Bertness MD, Yund PO, Brown AF (1983) Snail grazing and the abundance of algal crusts on a sheltered New England rocky beach. J Exp Mar Biol Ecol 71:147-164

Brewer RH (1978) Larval settlement in Aurelia aurita. Estuaries 1:120-122

Buchholz H (1951) Die Larvenformen von Balanus improvisus. Kiel Meeresforsch 12:49-57

Caley MJ, Carr MH, Hixon MA, Hughes TP, Jones GP, Menge BA (1996) Recruitment and the local dynamics of open marine populations. Annu Rev Ecol Syst 27: 477-500

Crisp DJ (1955) The behavior of barnacle cyprids in relation to water movement over a surface. J Exp Mar Biol 32: 569-590

Crisp DJ, Barnes H (1954) The orientation and distribution of barnacles at settlement with particular reference to surface contour. J Anim Ecol 23:142-163

Crisp DJ, Bourget E (1985) Growth in barnacles. Adv Mar Biol 22:199-244

Denny MW (1988) Biology and the mechanics of the waveswept environment. Princeton Univ. Press, Princeton, NJ

Dudley TL, D'Antonio CM (1991) The effects of substratum texture, grazing, and disturbance on macroalgal establishment in streams. Ecology 72(1):297-309

Fretter V, Graham A (1962) The British prosobranch molluscs. Ray Society, London

Gaines SD, Bertness M (1993) The dynamics of juvenile dispersal: why field ecologists must integrate. Ecology $74(8)$ : 2430-2435

Gosselin LA, Qian PY (1997) Juvenile mortality in benthic marine invertebrates. Mar Ecol Prog Ser 146:265-282

Hadfield MG (1986) Settlement and recruitment of marine invertebrates: a perspective and some proposals. Bull Mar Sci 39:418-425

Harlin MM, Lindbergh JM (1977) Selection of substrata by seaweeds: optimal surface relief. Mar Biol 40:33-40

Hawkins SJ (1981) The influence of season and barnacles on the algal colonization of Patella vulgata exclusion areas. J Mar Biol Assoc UK 61:1-15

Hawkins SJ, Hartnoll RG (1983) The influence of barnacle cover on the numbers, growth and behaviour of Patella Vulgata on a vertical pier. J Mar Biol Assoc UK 62: 855-867

Hills JM, Thomason JC (1996) A multiscale analysis of settlement density and pattern dynamics of the barnacle Semibalanus balanoides. Mar Ecol Prog Ser 138:103-115

Hills JM, Thomason JC (1998) The effect of scales of surface roughness on the settlement of barnacle (Semibalanus balanoides) cyprids. Biofouling 12(1-3):57-69

Hills JM, Thomason JC, Muhl J (1999) Settlement of barnacle larvae is governed by Euclidean and not fractal surface characteristics. Funct Ecol 13:868-875

Holm ER (1990) Effects of density-dependent mortality on the relationship between recruitment and larval settlement. Mar Ecol Prog Ser 60:141-146

Huxley R, Holland DL, Crisp DJ (1984) Influence of oil shale on intertidal organisms: effect of oil shale surface roughness on settlement of the barnacle Balanus balanoides (L.). J Exp Mar Biol Ecol 82:231-237

Janssen HH, Triebskorn R (1987) Comparative morphology of the radulae in Pomatias elegans and in Littorina littorea (Gastopoda: Taenioglossa). Zool Anz 219:73-82

Jernakoff P (1982) Factors affecting the recruitment of algae 
in a midshore region dominated by barnacles. J Exp Mar Biol Ecol 67:17-31

Keough MJ (1983) Patterns of recruitment of sessile invertebrates in two subtidal habitats. J Exp Mar Biol Ecol 66(3): 213-245

Keough MJ, Downes BJ (1982) Recruitment of marine invertebrates: the role of active larval choice and early mortality. Oecologia 53:348-352

Knight-Jones EW, Crisp DJ (1953) Gregariousness in barnacles in relation to the fouling of ships and to the antifouling research. Nature 171:1109-1110

Koehler J, Hansen PD, Wahl M (1999) Colonization patterns at the substratum-water interface: how does surface microtopography influence recruitment patterns of sessile organisms. Biofouling 14(3):237-248

Lenz M (1998) Verteidigungsmechanismen der Miesmuschel Mytilus edulis gegen Aufwuchs. PhD thesis, Universität Kiel

Lubchenco J (1983) Littorina and Fucus: effects of herbivores, substratum heterogenity and plant escapes during succession. Ecology 64(5):1116-1123

Menge B (1991) Relative importance of recruitment and other causes of variation in rocky intertidal community structure. J Exp Mar Biol Ecol 146:69-100

Norton TA, Fetter R (1981) The settlement of Sargassum muticum propagules in stationary and flowing water. J Mar Biol Assoc UK 61:929-940

Nusch EA (1980) Comparison of different methods for chlorophyll and phaeopigment determination. Arch Hydrobiol Beih Ergebn Limnol 14:14-36

Pawlik JR (1993) Marine invertebrate chemical defenses. Chem Rev 93(5):1911-1922

Pawlik JR, Butman CA (1993) Settlement of a marine tubeworm as a function of water velocity: interacting effects

Editorial responsibility: Otto Kinne (Editor),

Oldendorf/Luhe, Germany of hydrodynamics and behavior. Limnol Oceanogr 38(8): $1730-1740$

Petraitis PS (1983) Grazing patterns of the periwinkle and their effect on sessile intertidal organisms. Ecology 64(3): $522-533$

Petraitis PS (1987) Factors organizing rocky intertidal communities of New England: herbivory and predation in sheltered bays. J Exp Mar Biol Ecol 109:117-136

Petraitis PS (1990) Direct and indirect effects of predation, herbivory and surface rugosity on mussel recruitment. Oecologia 83:405-413

Raimondi PT (1988) Rock type affects settlement, recruitment, and zonation of the barnacle Chthamalus anisopoma (Pilsbury). J Exp Mar Biol Ecol 123:253-267

Steneck RS, Watling L (1982) Feeding capabilities and limitation of herbivorous molluscs: A functional group approach. Mar Biol 68:299-319

Wahl M (2001) Small scale variability of benthic assemblages: biogenic neighborhood effects. J Exp Mar Biol Ecol 258: 101-114

Wahl M, Sönnichsen H (1992) Marine epibiosis. IV. The periwinkle Littorina littorea lacks typical antifouling devices - why are some populations so little fouled? Mar Ecol Prog Ser 88:225-235

Walters LJ, Hadfield MG, Smith CM (1996) Waterborne chemical compounds in tropical macroalgae: positive and negative cues for larval settlement. Mar Biol 126(3): 383-393

Wethey DS, (1986) Ranking of settlement cues by barnacle larvae: influence of surface contour. Bull Mar Sci 39: $393-400$

Witman JD (1985) Refuges, biological disturbances and rocky subtidal community structure in New England. Ecol Monogr 55(4):421-445

Submitted: July 27, 2000; Accepted: April 5, 2001

Proofs received from author(s): January 7, 2002 